\title{
Coexistence of anomalies in the termination of facial artery and the origin of transverse facial artery. A case report
}

\author{
Chauhan, P. $^{1 *}$ and Kalra, S. ${ }^{2}$ \\ ${ }^{1}$ Department of Anatomy, Shri Guru Ram Rai Institute of Medical and Health Sciences - SGRRIH\&MS, \\ Patel Nagar, Dehradun, Uttarakhand- 248001, India \\ ${ }^{2}$ Department of Anatomy, University College of Medical Sciences, Delhi-110095, India \\ *E-mail: drpujachauhan@yahoo.co.in
}

\begin{abstract}
Several studies in the past have shown variations in the vessels of facial region. Facial artery may show variations in its origin, course, termination and branching pattern. Undocumented termination of facial artery as inferior labial artery and transverse facial artery emerging as a branch of maxillary artery was observed in the present study. Also, associated with it two distinct facial veins were also observed. To our knowledge, coexistence of this anomalous branching pattern has not been reported in the literature. A thorough knowledge about normal as well as variant vascular anatomy is crucial for interpretation of various interventional vascular procedures and performing surgical explorative procedures in this region including plastic surgery.
\end{abstract}

Keywords: facial artery, transverse facial artery, inferior labial artery, facial flap, facial vein.

\section{Introduction}

The facial artery in general arises anteriorly from the external carotid in the carotid triangle on top of lingual artery and directly above the greater cornu of hyoid bone. Medial to mandible it arches upwards and grooves the posterior aspect of the submandibular gland; it then turns down yet again between the gland and the medial pterygoid muscle. It enters the face after piercing the investing layer of deep cervical fascia. Reaching the surface of the mandible it curves round its inferior border, anterior to masseter muscle, to enter the face (BANNISTER, BERRY, COLLINS et al., 2005). Here it ascends forwards across the mandible and buccinators muscle to traverse a cleft in the modiolus near the buccal angle. It then ascends the side of the nose and ends at the medial palpebral fissure, supplying the lacrimal sac and anastomosing with the dorsal nasal branch of the ophthalmic artery. The artery is very tortuous all through: in the neck possibly to adapt to the movements of the pharynx during deglutition and on the face to movements of the mandible, lips and cheeks. Its branches include cervical and facial. The cervical branches include ascending palatine, tonsillar, glandular to submandibular gland and submental which is the largest submental branch. The facial branches include inferior labial, superior labial and lateral nasal. Distal to its superior branch i.e., lateral nasal it is termed the angular artery.

Transverse Facial Artery as a rule arises before the superficial temporal emerges from the parotid gland, it traverses the gland, crosses the masseter between the parotid duct and the zygomatic arch, accompanied by one or two facial nerve branches, and divides into numerous branches supplying the parotid gland and duct, masseter and skin, anastomosing with the facial, masseteric, buccal, lacrimal and infraorbital arteries (BANNISTER, BERRY, COLLINS et al., 2005).

\section{Materials and Methods}

The study involved dissection of a 60-year-old male cadaver in head and neck region for routine gross anatomy teaching purpose for undergraduate medical students. The body was preserved by the injection of a formalin based preservative ( $10 \%$ formalin). Bilateral common carotid arteries, branches of external carotid arteries and facial arteries were dissected.

\section{Case report}

The study revealed striking vascular anomalies in facial region (Figure 1). The left facial artery was traversing an anomalous course. It took origin from the external carotid artery, made a loop in the submandibular region, entered the face by winding around the lower border of mandible, and terminated as the inferior labial artery (ILA). There were no further branches being given by it. The maxillary artery on the left side was giving unusually large transverse facial artery measuring $7.5 \mathrm{~cm}$ in length and $0.5 \mathrm{~cm}$ in diameter. It was supplying arterial supply to rest of the face, which is usually given by facial artery. This aberrant transverse facial branch of maxillary artery was giving two terminal branches namely, an artery to angle of mouth, angular labial artery (ALA) and superior labial artery (SLA). The lateral nasal artery and angular artery which are the usual branches of facial artery were absent on this side. Also, on the left side there were two facial veins at a distance of $0.5 \mathrm{~cm}$ apart commencing at the medial angle of the eye which were joining to form a single common facial vein posterior to transverse facial artery almost $3 \mathrm{~cm}$ lateral to angle of mouth. To our knowledge, coexistence of these anomalies namely, facial artery terminating as inferior labial artery, transverse facial artery emerging as a branch of maxillary artery and presence of two distinct facial veins has not been reported in the literature. On the right side the origin, course and branching pattern of the facial artery as well as facial vein was normal. In addition, 


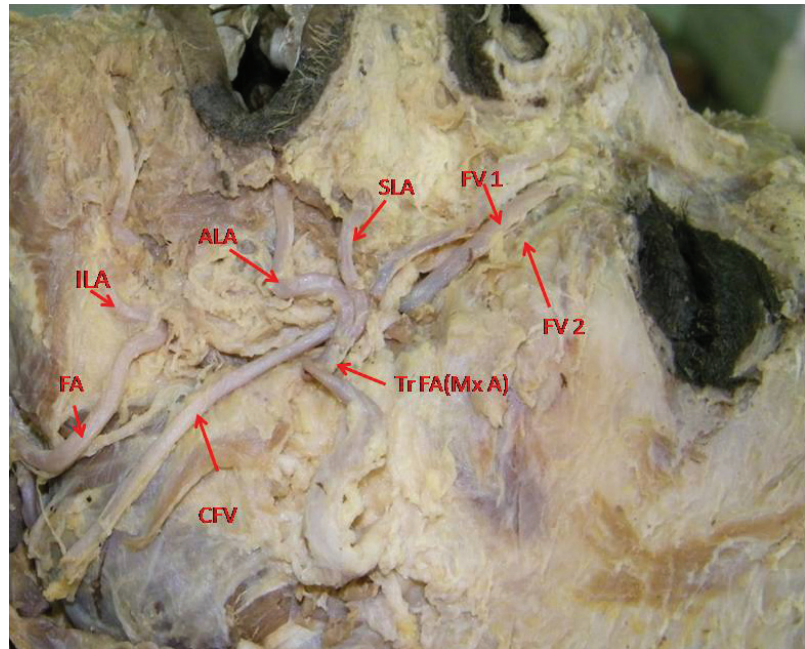

Figure 1. Left lateral view of face. FA - Facial artery, ILA - Inferior labial artery, $\operatorname{Tr}$ FA (Mx A) - Transverse facial artery, a branch coming from maxillary artery, SLA - Superior labial artery, ALA - Angular labial artery, FV 1 - Facial vein 1, FV 2 - Facial vein 2, CFV - Common facial vein.

there was no other obvious anomaly observed in this cadaver. This anomaly may provide useful information for clinical applications in different fields of Head and neck surgery. A thorough knowledge about normal as well as variant vascular anatomy is crucial for interpretation of various interventional vascular procedures and performing surgical explorative procedures in this region including plastic surgery.

\section{Discussion}

Several studies in the past have shown variations in the vessels of facial region. Facial artery may show variations in its origin, course, termination and branching pattern. Unilateral agenesis of the facial artery with compensation by a giant transverse facial artery has been reported in the literature (TUBBS, SALTER and OAKES, 2005). This has been claimed that in the absence of facial artery, the transverse facial artery, ophthalmic artery and maxillary artery will supply its territory. Hypoplasia of the facial artery has been described. Soikkonen, Wolf, Hietanen et al. (1991) have shown that the size of facial artery and transverse facial artery are inversely proportional. Tubbs, Salter and Oakes (2005) described a cadaver with an apparently enlarged transverse facial artery that travelled to the angle of the mouth where it then assumed the normal course of the facial artery.

The main arterial supply of the facial skin envelope is the facial artery which serves as the main pedicle for a number of facial flaps, including facial transplant graft. In a study (LOHN, PENN, NORTON et al., 2011) on cadaveric dissections of 201 facial arteries and 198 facial veins explored the course of the facial artery and vein, their branching patterns, terminations, and anomalous variants. It was reported that all branches originated from a single facial arterial trunk in $86 \%$ and branching patterns were symmetrical in $53 \%$ of specimens. The facial artery predominantly terminated as a lateral nasal artery $(49 \%)$. The facial artery was undetectable in 5 cases, with transverse facial arterial dominance ( 1 case bilateral). The facial vein was predictable in position except for 2 instances, being replaced by a transverse facial vein (unilateral). Facial arterial dominance in facial blood supply is common but unpredictable. Careful vascular workup prior to facial transplantation and unipedicled flap procedures is therefore indispensable. In none of these cases the authors reported that facial artery was terminating as inferior labial artery or asymmetrical pattern of branching on two sides as observed in our study. In concurrence to our finding, authors (MARX, KUMAR, REDDY et al., 2008) have reported in a study on a 65-year-old male cadaver revealed bilateral anomalous facial artery. The right facial artery taking origin from the external carotid artery did not make any loop in the submandibular region, entered the face by winding round the lower border of mandible, and terminated as the inferior labial artery. The upper part of the right side face in this case was supplied by various branches of transverse facial artery, infra orbital artery and dorsal nasal artery. In this case contradictory to our finding it was reported that the origin, course and branching pattern of the left facial artery was normal except the missing inferior labial artery. The venous drainage of the face was normal on both sides which is also dissimilar to our finding. Although in the literature the transverse facial arising from the maxillary artery (ADACHI, 1928; SHINTANI, TERAKADO, ALCALDE et al., 1999) has been reported and even the presence of double facial vein has been observed independently (GOSLING, HARRIS and HUMPHERSON, 2008). But coexistence of all these anomalies of facial artery, transverse facial artery and double facial veins has not been reported. Other authors (LOUKAS, HULLETT, LOUIS JUNIOR et al., 2005) studied 284 hemifaces derived from 142 formalin fixed cadavers. They have categorized some variations in branching pattern of facial artery. These include five Types, labeled " $\mathrm{A}$ " through "E". Type A $(135,47.5 \%)$ : facial artery bifurcates into SLA and lateral nasal (the latter gives off inferior and superior alar and ends as angular); Type B (110, 38.7\%): similar to Type A, except lateral nasal terminates as superior alar (angular artery is absent); Type C $(24,8.4 \%)$ : facial artery terminates as SLA; Type D $(11,3.8 \%)$ : angular artery arises directly from facial arterial trunk rather than as the termination of lateral nasal, with the facial artery ending as superior alar; Type E $(4,1.4 \%)$ : facial artery terminates as a rudimentary twig without providing any significant branches. But none of these types reported is similar to our finding of facial artery terminating as inferior labial artery. Also, in the literature a functional analysis of the arterial blood supply of the face has been reported (BRÜE and BEY, 2000). According to this analysis, the anatomic variations observed are determined by regional hemodynamic balances. These variations influence the design and construction of local facial flaps, such as the submental, nasolabial and buccinator flap. They may also sway the concepts concerning the hemodynamics of arteriovenous malformations of the face

Though veins were generally less considered less important than arteries for various surgical intervention but now with progress in surgical techniques more and more veins are being used for graft purposes. Therefore, our finding of two facial veins is of immense surgical importance. Authors (SABHARWAL and MUKHERJEE, 1998) in a study of autogenous graft used common facial vein and external jugular veins patches for angioplasty thereby saving saphenous veins for other vascular procedures. They 
reported that even the outcome of facial vein or jugular vein patches were comparable and it also saved the co morbidity of groin incision.

\section{References}

ADACHI, B. Das Arteriensystem der Japaner. Kyoto: Kenkyusha Press, 1928. vol. 1, p. 83.

BANNISTER, LH., BERRY, MM., COLLINS, P., DYSON, M., DUSSEK, JE. and FERGUSON, MWJ. Gray's Anatomy. 38th ed. Elsevier Churchill Livingstone, 2005. p. 1515-1519.

BRÜE, E. and BEY, E. Facial artery. Embryological review, descriptive and functional anatomy based on a review of the literature. Annales De Chirurgie Plastique Esthetique, 2000, vol. 45, n. 4, p. 461-84. PMid:10989523.

GOSLING, JA., HARRIS, PF. and HUMPHERSON, JR. Human Anatomy. Color Atlas and Textbook, 2008. p. 7.

LOHN, JW., PENN, JW., NORTON, J. and BUTLER, PE .The course and variation of the facial artery and vein: implications for facial transplantation and facial surgery. Annals of Plastic Surgery, vol. 2011 , vol. 67 , n. 2 , p. 184-188.

LOUKAS, M., HULLETT, J., LOUIS JUNIOR, RG., KAPOS, T., KNIGHT, J., NAGY, R. and MARYCZ, D. A detailed observation of variations of the facial artery, with emphasis on the superior labial artery. Surgical and Radiologic Anatomy, 2006, vol. 28, n. 3, p. 316-324. PMid:16547605. http://dx.doi.org/10.1007/ s00276-006-0093-0
MARX, C., KUMAR, P., REDDY, S. and VOLLALA, VR . Bilateral variation of facial artery: a case report. Romanian Journal of Morphology and Embryology, 2008, vol. 49, n. 3, p. 399-401. PMid:18758647.

SABHARWAL, P. and MUKHERJEE, D. Autogenous common facial vein or external jugular vein patch for carotid endarterectomy. Cardiovascular Surgery, 1998, vol. 6, n. 6, p. 594-597. http:// dx.doi.org/10.1016/S0967-2109(98)00084-2

SHINTANI, S., TERAKADO, N., ALCALDE, RE., TOMIZAWA, K., NAKAYAMA, S., UEYAMA, Y., ICHIKAWA, H., SUGIMOTO, T. and MATSUMURA, T. An anatomical study of the arteries for intraarterial chemotherapy of head and neck cancer. International Journal of Clinical Oncology, 1999, vol. 4, n. 6, p. 327-330. http:// dx.doi.org/10.1007/s101470050079

SOIKKONEN, K., WOLF, J., HIETANEN, J. and MATTILA, K. Three main arteries of the face and their tortuosity. British Journal of Oral and Maxillofacial Surgery, 1991, vol. 29, n. 6, p. 395-398. http://dx.doi.org/10.1016/0266-4356(91)90009-T

TUBBS, RS., SALTER, EG. and OAKES, WJ. Unilateral agenesis of the facial artery with compensation by a giant transverse facial artery. Folia Morphologica, 2005, vol. 64, n. 3, p. 226-228.

Received June 23, 2013

Accepted April 6, 2014 